\title{
Marginal zone lymphomas involving meningeal dura: possible link to IgG4-related diseases
}

Girish Venkataraman ${ }^{1, *}$, Kathryn A Rizzo ${ }^{1, \dagger}$, Jessica J Chavez ${ }^{1}$, Berthold Streubel ${ }^{2}$, Mark Raffeld ${ }^{1}$, Elaine S Jaffe ${ }^{1}$ and Stefania Pittaluga ${ }^{1}$

${ }^{1}$ Laboratory of Pathology, Center for Cancer Research, National Cancer Institute, National Institutes of Health, Bethesda, MD, USA and ${ }^{2}$ Institute of Pathology, Vienna General Hospital, Medical University of Vienna, Vienna, Austria

Dura-based marginal zone lymphomas represent an uncommon group of low-grade B-cell neoplasms, and literature regarding the clinical, histological and genetic profile of these tumors in the context of the newly described IgG4-related entities is lacking. We analyzed 32 dura-based marginal zone lymphomas identified in 27 females and 5 males ranging in age from 33-82 years (median 50). Morphologic examination, immunohistochemical studies and PCR for B-cell clonality were carried out in all cases. In addition, IgG4 immunohistochemistry and cytogenetic studies (either by FISH or RT-PCR) were carried out in 20 (18 primary dural; 2 with associated extradural disease) and 9 cases, respectively. Clinically, most cases presented radiologically as dura-based masses, mimicking meningioma. Histologically, the majority exhibited plasmacytoid differentiation, and were clonal either by PCR or immunohistochemical light chain analysis (28 out of 32). In the subset tested for lgG4, 6 of 18 primary dural marginal zone lymphoma (including one epidural tumor) showed numerous IgG4-positive plasma cells; all 6 were light chain restricted and clonal by PCR in 5 of 6 tested cases. Three IgG4-positive marginal zone lymphomas tested for cytogenetics did not show any cytogenetic aberrations. Across all cases, FISH and RT-PCR identified abnormalities in three out of nine cases (trisomies 3 and 18; trisomies 3 and 1; trisomy 18) without any extranodal marginal zone lymphoma specific translocations. Regardless of the treatment modality, 16 of 17 patients with follow-up are alive without evidence of disease over a period of 4-124 months (median 19.5). The expression of IgG4 in light-chain-restricted clonal plasma cells of a significant subset of dural marginal zone lymphomas, including one in an epidural location, is a novel finding and points to distinctive biology. Cytogenetic aberrations are present only in a minority of dural marginal zone lymphomas.

Modern Pathology (2011) 24, 355-366; doi:10.1038/modpathol.2010.206; published online 19 November 2010

Keywords: dura; IgG4; immunohistochemistry; inflammatory pseudotumor; marginal zone lymphoma; RT-PCR; trisomy 3

Extranodal marginal zone lymphomas in the dural location are a rare subgroup of lymphomas. Most

Correspondence: Dr S Pittaluga, MD, PhD, Laboratory of Pathology, Center for Cancer Research, National Cancer Institute, National Institutes of Health, 10, Center Drive, Building 10, Room 2B 42, Bethesda, MD 20892, USA.

E-mail: stefpitt@mail.nih.gov

${ }^{*}$ Current Address: Department of Pathology, Loyola University Medical Center, Maywood, IL, USA.

Current Address: Department of Pathology and Laboratory Medicine, Indiana University School of Medicine, Indianapolis, IN, USA.

Received 17 June 2010; revised 29 August 2010; accepted 30 August 2010; published online 19 November 2010 reported cases occur in middle age women with a radiological presentation mimicking meningioma, ${ }^{1-4}$ and exhibit histological and immunophenotypic features similar to other extranodal marginal zone lymphoma. Irrespective of the treatment modality, they have been reported in published series to have an excellent outcome..$^{5-7}$

Among the recurrent cytogenetic abnormalities described in mucosa-associated lymphoid tissue (MALT) lymphomas, only trisomy 3 was detected in dural marginal zone lymphomas in a large series, ${ }^{7}$ whereas trisomy 18 and translocations, such as $\mathrm{t}(11 ; 18)(\mathrm{q} 21 ; \mathrm{q} 21)$ and $\mathrm{t}(14 ; 18)(\mathrm{q} 32 ; \mathrm{q} 21)$ involving API2-MALT and immunoglobulin heavy-chain-joining 
region (IGH)-MALT, respectively, were not detected ${ }^{7}$ with the exception of one report describing presence of IGH-MALT1 at this location. ${ }^{8}$ This finding is not surprising, given that MALT lymphomas have site-specific differences in the frequencies of the various cytogenetic abnormalities; lung MALT lymphomas (and to a lesser extent gastric MALT lymphomas) frequently harbor the API2-MALT, ${ }^{9}$ whereas orbital MALTs ${ }^{10}$ are known to often harbor translocations involving IGH@. ${ }^{11}$ MALT lymphomas arise in the background of chronic inflammation and autoimmune conditions with chronic Helicobacter pylori gastritis or Hashimoto's thyroiditis, representing quintessential examples for harbingers of marginal zone lymphoma in their respective locations.

Analogous to the evolution of MALT lymphomas, another entity recently reported in the context of chronic inflammation and associated polyclonal plasmacytosis is 'IgG4-related sclerosing disease'a term proposed initially by Kamisawa et $a l^{12}$ in the context of autoimmune pancreatitis. These lesions were originally identified in the context of destructive 'mass-forming' lesions associated with marked sclerosis and infiltration of numerous plasma cells of the IgG4 subclass, accompanied by elevated serum IgG4. Over the last few years, a number of subsequent studies have expanded the spectrum of IgG4-related diseases from autoimmune pancreatitis $^{13}$ to include similar lesions occurring in the lacrimal glands, ${ }^{14}$ submandibular glands, ${ }^{15}$ hepatobiliary tracts ${ }^{16,17}$ and lymph nodes. ${ }^{18}$ The presence of nervous system involvement by this entity was recently described by Chan et al, ${ }^{19}$ who reported the occurrence of an IgG4-rich sclerosing process with polytypic plasma cells in a 37-year-old man, who presented with a thoracic dural mass; this mass lesion was characterized by numerous IgG4-positive plasma cells, phlebitis and sclerosis, and was termed as 'IgG4-related sclerosing pachymeningitis'. Since then, it has become apparent that these processes often can be part of an autoimmune or systemic disorder ${ }^{20-22}$ with a significant potential for steroid responsiveness, highlighting the need to distinguish these entities from other inflammatory conditions that have a similar presentation and may not respond as favorably. ${ }^{23}$

Given the commonality in the predisposing factors for both IgG4-related sclerosing disease and MALT lymphomas, it is conceivable that an increased risk for MALT lymphoma may be expected in the background of IgG4-related sclerosing disease. Cheuk et $a l^{24}$ described cases of IgG4+ marginal zone lymphoma occurring in the ocular adnexae, and identified the occurrence of lymphoma in up to $10 \%$ of the patients with preexisting IgG4-related sclerosing disease, although the relationship with the previous IgG4-related sclerosing disease components was not entirely resolved insofar, as the previous IgG4-related sclerosing disease components were polytypic with respect to light chains. In another series examining ocular adnexal IgG4-related sclerosing disease, Sato et $a 1^{25}$ identified two clonal proliferations by Southern blot among 17 cases ( $12 \%$ incidence rate of lymphoma), although light chains were not examined.

In light of the literature pertaining to IgG4-related sclerosing disease and marginal zone lymphomas, we investigated whether IgG4 expression is present and may have a role in dural marginal zone lymphoma. To this end, we analyzed 32 cases of dura-based marginal zone lymphoma by morphology, immunohistochemistry (with specific emphasis on IgG4) and molecular studies. In a minority of cases, we also sought to uncover cytogenetic abnormalities by FISH and RT-PCR testing.

\section{Materials and methods}

\section{Case Selection}

We reviewed cases submitted to the laboratory of Pathology at the NCI as dura-based masses with suspicion for a B-cell lymphoma, including the series of five cases (cases 1-5; Table 1) previously reported. ${ }^{5}$ These cases were culled from the consultation files of the Hematopathology Section between 1985 and 2009 (19 of 26 cases were resections/excisions; 7 of 26 were biopsies). All cases were submitted in consultation from outside physicians. This study was approved by the Institutional Review Board of the National Cancer Institute (IRB-NCI-10-C-074).

Cases selected for inclusion in the study comprised two groups:

(A) Primary marginal zone lymphoma occurring in an intracranial dural location, except one case occurring in a thoracic epidural location, with no other known sites of involvement (cases 1-5 initial series; cases 6-28).

(B) Marginal zone lymphoma involving the cranial dura with associated extra-cranial sites of involvement (cases 29-32). These cases had either previous/concurrent (three out of four), or subsequent (one out of four) extradural disease that was histologically confirmed.

In addition, we included three cases of inflammatory pseudotumor/plasma cell granuloma involving the dura to provide a comparative analysis with the larger cohort with respect to histological features and IgG4 staining detailed below. Follow-up was obtained where possible from the referring pathologist, oncologist or neurosurgeon. Basic demographic data and descriptive statistics were summarized using SAS 9.2 (SAS Institute, Cary, NC, USA).

\section{Histology and Immunohistochemistry}

We reviewed hematoxylin and eosin ( $\mathrm{H}$ and $\mathrm{E}$ )stained sections from formalin-fixed paraffinembedded tissues. In addition, immunoperoxidase 
Table 1 Clinical and radiological features of marginal zone lymphoma patients

\begin{tabular}{|c|c|c|c|c|c|c|}
\hline Case no. & Age/sex & Location(s) & Radiology & Treatment & $\begin{array}{l}\text { Remission/ } \\
\text { outcome }\end{array}$ & $\begin{array}{c}\text { Duration of PR/CR } \\
\text { (months) }\end{array}$ \\
\hline 1 & $40 / \mathrm{F}$ & Cavernous sinus & Mass & RT & CR/ANED & 63 \\
\hline 2 & $62 / \mathrm{F}$ & Parietal, bilateral & Thickening & Fludarabine & CR/ANED & 22 \\
\hline 3 & $52 / \mathrm{F}$ & Frontal & Mass & RT, MTX, ARA-C & CR/ANED & 7 \\
\hline 4 & $43 / \mathrm{F}$ & Tentorium & Mass & RT & CR/ANED & 9 \\
\hline 5 & $57 / \mathrm{F}$ & Anterior falcine & Mass & $\mathrm{RT}$ & CR/ANED & 14 \\
\hline 6 & $37 / \mathrm{F}$ & Not known & Mass & & & \\
\hline 7 & $44 / \mathrm{M}$ & Frontal & Thickening & & & \\
\hline 8 & $53 / \mathrm{M}$ & Posterior fossa, bilateral & Mass & None & CR/ANED & 17 \\
\hline 9 & $42 / \mathrm{F}$ & Not known & Unknown & & & \\
\hline 10 & $53 / \mathrm{M}$ & Parietal & Lytic bone lesion & RT & CR/ANED & 36 \\
\hline 11 & $47 / F$ & Not known & Mass & & & \\
\hline 12 & $46 / \mathrm{F}$ & Cavernous sinus & Mass & RT & CR/ANED & 62 \\
\hline 13 & $59 / \mathrm{F}$ & Tentorium & Mass & & & \\
\hline $14^{\mathrm{a}}$ & $61 / \mathrm{F}$ & Posterior fossa & Thickening & Steroids & CR/ANED & 5 \\
\hline 15 & $45 / \mathrm{F}$ & Frontal & Mass & Observation & CR/ANED & 4 \\
\hline 16 & $48 / \mathrm{F}$ & Frontal & Mass & & & \\
\hline 17 & $57 / \mathrm{F}$ & Fronto-temporal, multiple & Mass & RT, steroids, rituxan & CR/ANED & 5 \\
\hline 18 & $50 / \mathrm{F}$ & Not known & Mass & & & \\
\hline 19 & $66 / \mathrm{F}$ & Frontal & Mass & & & \\
\hline 20 & $44 / F$ & Temporal & Mass & & & \\
\hline 21 & $73 / \mathrm{F}$ & Not known & Mass & & & \\
\hline 22 & $56 / \mathrm{F}$ & Occipital & Mass & RT, steroids & CR/ANED & 30 \\
\hline 23 & $31 / \mathrm{F}$ & Not known & Unknown & & & \\
\hline 24 & $71 / \mathrm{M}$ & Parietal & Mass & Observation & CR/ANED & 16 \\
\hline 25 & $42 / \mathrm{F}$ & Occipital & Mass & ?RT & PR/AWD & 6 \\
\hline 26 & $40 / F$ & Middle cranial fossa & Mass & & & \\
\hline 27 & $42 / \mathrm{F}$ & Parieto-temporal & Mass & RT, MTX & CR/ANED & 96 \\
\hline 28 & $36 / \mathrm{F}$ & Thoracic spine & Mass, epidural & & & \\
\hline \multicolumn{7}{|c|}{ Cases with associated extradural disease } \\
\hline 29 & $52 / \mathrm{M}$ & Parietal & Mass & RT & CR/ANED & 36 \\
\hline 30 & $45 / \mathrm{F}$ & Temporal & Mass & None & CR/ANED & 124 \\
\hline 31 & $51 / \mathrm{F}$ & Not known & Mass & & & \\
\hline 32 & $50 / \mathrm{F}$ & Parietal & Thickening & & & \\
\hline
\end{tabular}

Abbreviations: ANED, alive with no evidence of disease; ARA-C, cytosine arabinoside; AWD, alive with disease; CR, complete remission; MTX, methotrexate; PR, partial remission; RT, radiotherapy.

${ }^{\mathrm{a}}$ Reported recently by Shaia et $a .^{44}$

staining was performed using the following antibody panel: CD20 (clone L26), CD3 (clone F7.2.38), CD79a (clone MB1), MUM-1 (clone MUM1p), CD43 (clone DF-T1), IgG, IgA, IgM, IgD, $\kappa$-, $\lambda$-light chains (heavy and light chains, rabbit polyclonal) and bcl2 (clone 124), all from DAKO (Dako, Carpinteria, CA, USA). Staining was performed on an automated immunostainer, using DAKO or Ventana according to the manufacturer's instructions with EnvisionPlus System-HRP and ultraView Universal DAB detection kit, respectively. Antigen retrieval was performed using either $10 \mathrm{mM}$ citrate at $\mathrm{pH} 6$ or high pH (with EDTA pH9.0 or Dako high pH).

IgG4 staining and evaluation

In addition, IgG4 testing could be performed on 20 cases with available tissue sections. IgG4 immunohistochemistry was performed manually using the primary antibody (mouse monoclonal; clone HP6025; Invitrogen, Carlsbad, CA, USA) at a dilution of 1:1000 for a $30 \mathrm{~min}$ incubation at room temperature with a low $\mathrm{pH}$ (6.1) antigen retrieval in a proprietary Target Retrieval Solution (TRS; Dako).
Controls for IgG4 included normal tonsils and tissue from case of IgG4-related autoimmune pancreatitis reported previously by Yamamoto et al $;{ }^{26}$ unstained slides of the latter were a kind gift of Hidetaka Yamamoto (Kyushu University, Kyushu, Japan).

For estimating IgG4, absolute numbers of strongly positive IgG4-positive plasma cells as well as ratio of IgG4-positive plasma cells to total IgG-positive plasma cells in the same area of a $\times 40$ field of an Olympus BX50 microscope were estimated off the images using a cell counter macro within the Image J platform (open-source software available at http:// rsbweb.nih.gov/ij/). Specifically, we use absolute numbers of positive cells/HPF and not ordinal cutoff points for defining positivity inasmuch as most previous studies evaluating IgG4 were in the context of sclerosing diseases, whereas all cases comprising our cohort were marginal zone lymphomas with varying degrees of plasmacytic differentiation. In all cases positive for IgG4, quantitative comparison and comparison with the spatial distribution of the light-chain-restricted population was also carried out visually. 


\section{Immunoglobulin PCR for Clonality Assessment}

In cases with available paraffin-embedded tissue, DNA extraction was performed using either a commercially available resin, GeneReleaser (Bioventures, Murfreesboro, TN, USA) for cases before July 2009, or using a QiaCUBE extraction platform using their proprietary buffer and proteinase $\mathrm{K}$ digestion.

For some cases, before July 2009, only data from IGH locus testing was available with no further material available for testing at the IG $\kappa$ locus. In these cases, PCR was performed using primers directed to the $\mathrm{JH}$ and $\mathrm{VH}$ framework (FR) III consensus primers and/or FR region II and the IGH (FRII-IGH PCR), according to the method of Ramasamy et $a{ }^{27}$ To control for the amplification ability of each sample, PCR was performed for glyceraldehyde-3-phosphate dehydrogenase. In more recent cases after July 2009, and few earlier cases with available tissue examined more recently, testing for the IG $\kappa$ locus was additionally performed using the Biomed II primer set described by van Dongen et $a l^{28}$ and supplied by InVivoScribe Technologies (IGK Gene Clonality Assay-ABI Fluorescence Detection). These reactions interrogate rearrangements involving the $\mathrm{V} \kappa$ loci and $\mathrm{J} \kappa$ (tube $\mathrm{A}$ ), the $\mathrm{V} \kappa$ locus and the $\kappa \mathrm{DE}$ locus (tube B), and the $\kappa$-intron RSS locus and the $\kappa \mathrm{DE}$ locus (tube $\mathrm{B}$ ).

The products from all reactions were analyzed by either capillary electrophoresis on an ABI 3130 Genetic Analyzer, with electropherograms analyzed using GeneMapper software version 3.7 (ABI) in recent cases or by $16 \%$ non-denaturing polyacrylamide gel electrophoresis (in older cases) and visualized with ethidium bromide staining.

\section{Detection of $t(11 ; 18)(q 21 ; q 21)$ by RT-PCR}

RNA was isolated from archival formalin-fixed, paraffin-embedded lymphoma tissues. Total RNA was extracted from $10 \mu \mathrm{m}$ sections with a high pure RNA paraffin kit (Roche Diagnostics, Mannheim, Germany). First-strand cDNA was synthesized from $1 \mu \mathrm{g}$ total RNA with a superscript first-strand synthesis system (Invitrogen) using random hexamers as primers. RT-PCR for the detection of the API2MALT1 fusion transcript was performed according to Inagaki et $a l^{29}$ with one modification: first round RT-PCR products were amplified in a second round separately and not as multiplex nested PCRs, in order to discriminate the various fusion signals. Where indicated, PCR products were sequenced using Rhodamine dye terminators on an ABI Prism 310 (PE Applied Biosystems, Foster City, CA).

\section{FISH Analysis}

In all cases with available formalin-fixed paraffinembedded tissue material, FISH was performed on single-cell suspensions isolated from paraffin blocks. FISH was performed on interphase nuclei with the following probe sets: for the detection of the $t(14 ; 18)(q 32 ; q 21)$ involving IGH and MALT1 P1 artificial chromosome (PAC) 152M5 (Spectrum Orange labeled) spanning the MALT1 gene and flanking regions and bacterial artificial chromosome (BAC) 158A2 were used; ${ }^{30}$ for rearrangements of BCL10 BACs RP11-1077C10 and RP11-36L4 centromeric to BCL10 and RP11-1080I1 and RP11-40K4 telomeric to BCL10 were used. ${ }^{31}$ Translocations of FOXP1 were investigated with BACs RP11-154H23 and RP11-215K24. ${ }^{11}$ Aberrations of IGH and BCL6 were examined with dual color break-apart probes (Vysis, Downer's Grove, IL, USA). For detection of trisomies 3, 12 and 18, we applied centromerespecific probes (Vysis).

The cut-off value for the diagnosis of each probe set was the mean percentage of cells with a falsepositive signal constellation plus three standard deviations, as assessed on tissue from 20 reactive lymph nodes.

\section{Results}

\section{Clinical Characteristics of Study Cases}

The salient presenting features of the 32 cases are summarized in Table 1 . There was a marked female predilection (27 out of 32 ; sex ratio of $5: 1$ ) with patients ranging in age from 33-82 years (median 50 years). The presenting symptoms were either nonspecific, such as headaches (1 out of 14) or related to mass effect, in the form of localized neurological defects in $58 \%$ ( 7 out of 14), seizures (5 out of 14 ) or syncope (3 out of 14).

At presentation, most cases showed radiological evidence of a dura-based mass, whereas a minority demonstrated meningeal thickening and one case (case 10) presented as a lytic lesion (see Table 1). Most of the cases were located in various intracranial locations including the frontal, parietal, temporal regions, cavernous sinus, tentorium as well as the posterior fossa. The preoperative diagnosis in most cases was a meningioma. In cases 11,27 and 31 the clinical diagnosis was sub-dural hematomas. Only one case (case 28) involved the thoracic spine. All cases in groups A presumably were clinically stage IE.

Group B included four cases also with extradural disease: three had concurrent involvement of the lung (case 30), the submandibular gland (case 31) or the skin of scalp (case 32). Case 32 also had a history of laryngeal low-grade B-cell lymphoma, consistent with marginal zone lymphoma diagnosed 2 years before the development of the dural mass, which was biopsied together with a concurrent scalp lesion. In the fourth case (case 29), mediastinal adenopathy developed 6 months after the dural lesion was excised, and resolved with further chemotherapy.

Treatment and follow-up information were obtained on 17 patients. Treatment modalities 
included biopsy/surgery, radiation and adjuvant chemotherapy; these were used either singly or in combination as detailed in Table 1 . The chemotherapy regimens included cyclophosphamide, doxorubicin, oncovin, prednisone and methotrexate, cytosine arabinoside, and rituximab. Notably, steroids were used in three cases with significant radiological improvement before the biopsy noted in case 22. With the exception of one (case 25), all

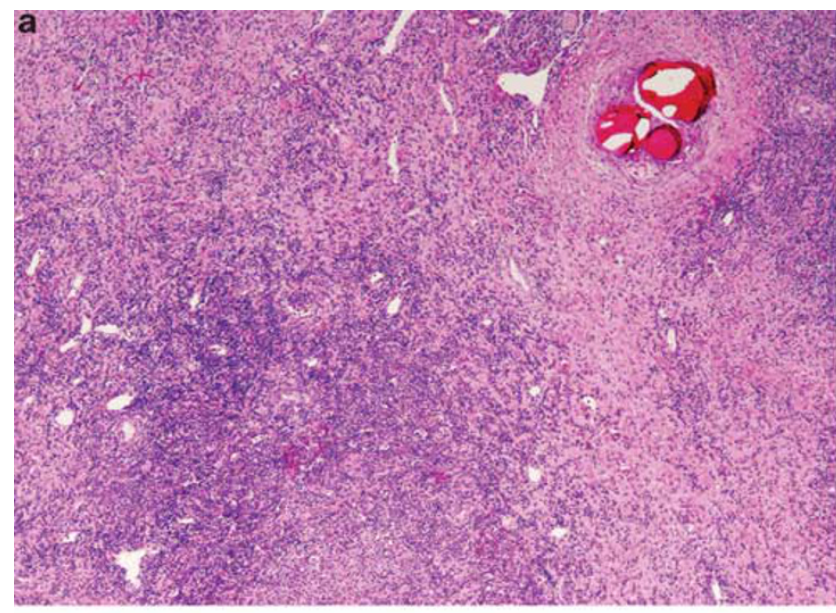

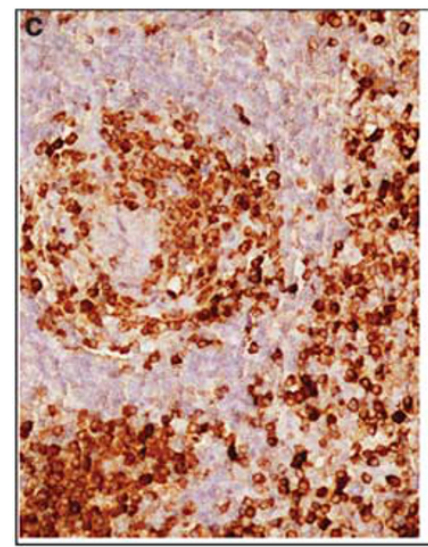

Kappa

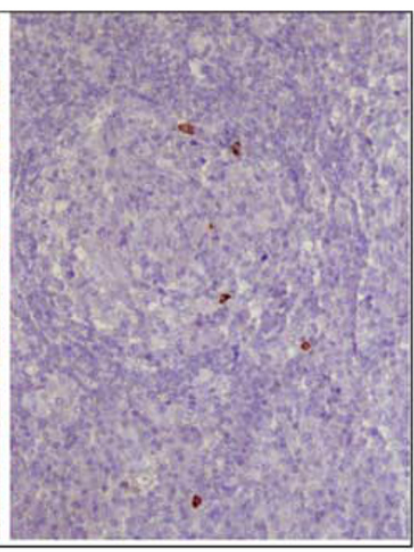

Lambda

patients were disease-free with a follow-up ranging from 4 to 124 months (Table 1).

\section{Histology, Immunophenotypic and Molecular Studies}

All cases across the two groups were characterized by a dense lymphoid infiltrate within dural tissue with intervening fibrous septae (Figure 1). Foci of incipient infarction related to therapeutically
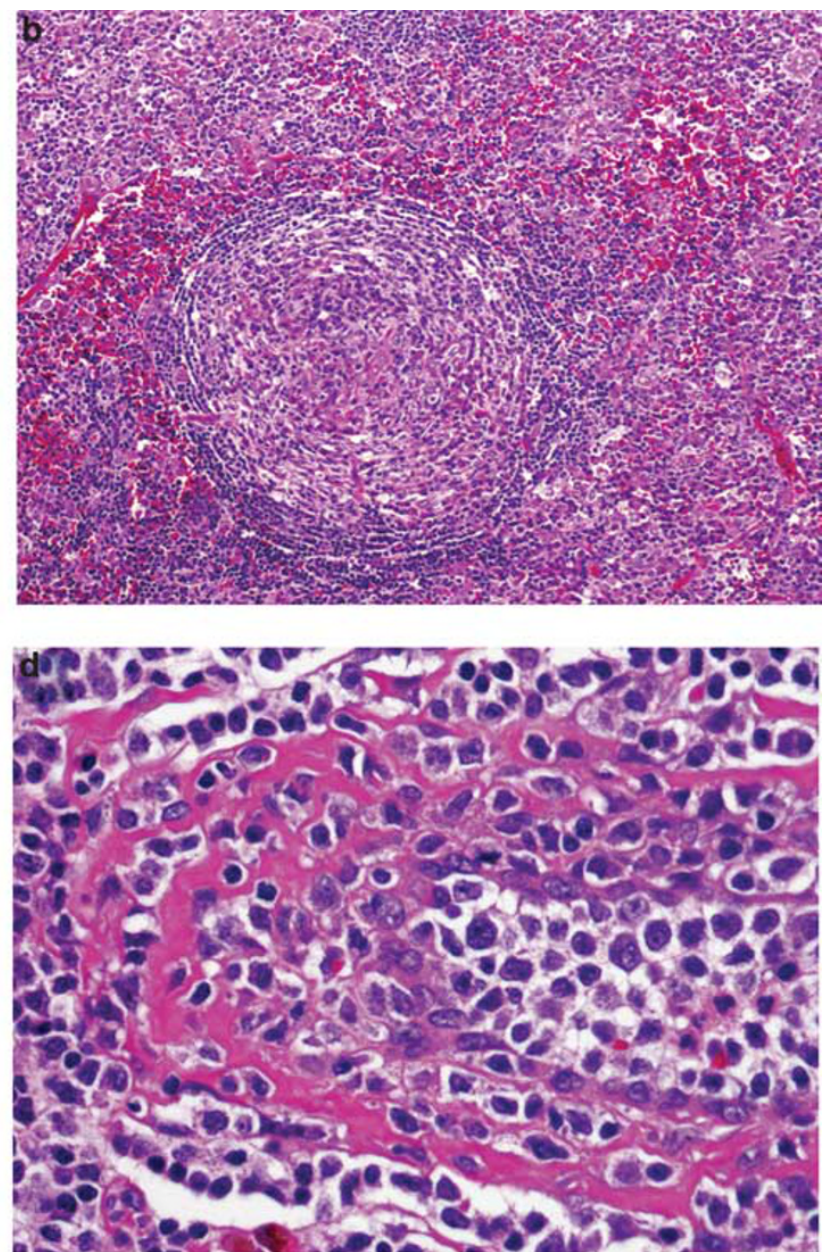

e
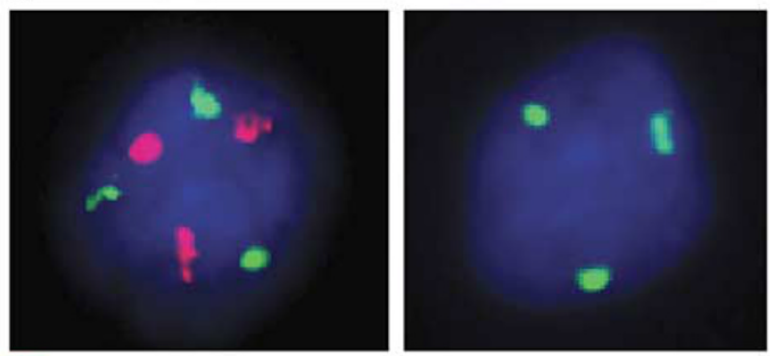

Chromosome 3 probe

Chromosome 18 probe

Figure 1 Marginal zone lymphoma of the dura. (a) Dense lymphoid infiltrate with areas of sclerosis (case 18) and evidence of therapeutically embolized vessels (upper right). (b) Case with lymphoid follicles, which were often colonized by plasmacytic cells. (c) This case shows $\kappa$-light-chain-restricted plasmacytic cells within and outside the follicles. (d) Case 23 with focal small vessel venulitis within the dural lymphoma. (e) Interphase FISH studies: (left panel) FISH demonstrating trisomies of 3 and 18; (right panel) FISH depicting three signal for chromosome 18 indicative of trisomy 18. 
embolized vascular channels were apparent in three cases (See Figure 1a). In 13 out of 32 cases, lymphoid follicles of varying sizes with reactive germinal centers were present with a monomorphous interfollicular infiltrate comprising small lymphocytic cells (Figure 1b). Overt monocytoid Bcell differentiation resembling that seen in nodal marginal zone lymphomas was not encountered. Varying degrees of plasmacytic differentiation was seen in most cases (28 out of 32) with follicular colonization by plasmacytic cells observed in some cases (5 out of 13; Figure 1c). One case (case 8) showed numerous Mott cells replete with abundant cytoplasmic immunoglobulin without follicular colonization (Figure 3). Although some cases showed a more heterogeneous cellular composition with a few larger cells, areas consistent with large cell transformation were not present.

In a small subset of cases, the tumor abutted brain parenchyma with a sharp distinction between the dural tumor and adjoining gray matter (Figure 2). One case showed limited involvement of the Virchow-Robin spaces in the immediate vicinity of the tumor (case 32; Figure 2a), whereas in two others there was more extensive involvement of either the adjacent brain parenchyma (case 25; Figure 2b-d) or cranial nerves (case 9). Case 28 involving the epidural space (Figure 4) was characterized by a dense, albeit crushed lymphoid infiltrate within fibroadipose connective tissue and focal obliterative phlebitis (Figure $4 \mathrm{~b}$ and $\mathrm{c}$ ). There were no distinguishing morphologic features between cases in the two groups.

By immunostaining in all cases, the neoplastic cells expressed CD20 and CD79a; the plasmacytic component marked with CD79a, and MUM-1. In many cases, numerous admixed T-cells were present. The Ki-67 proliferative index was low (10-20\%) with occasional larger cells highlighted. The neoplastic cells were largely negative for IgD (five out of six), which highlighted attenuated mantle zones in cases with reactive follicles. Although a few cases did not show apparent plasmacytic differentiation on the $\mathrm{H}$ and $\mathrm{E}$ stained slides, staining for $\kappa$-/ $\lambda$-light chains revealed the presence of a distinct underlying light-chain-
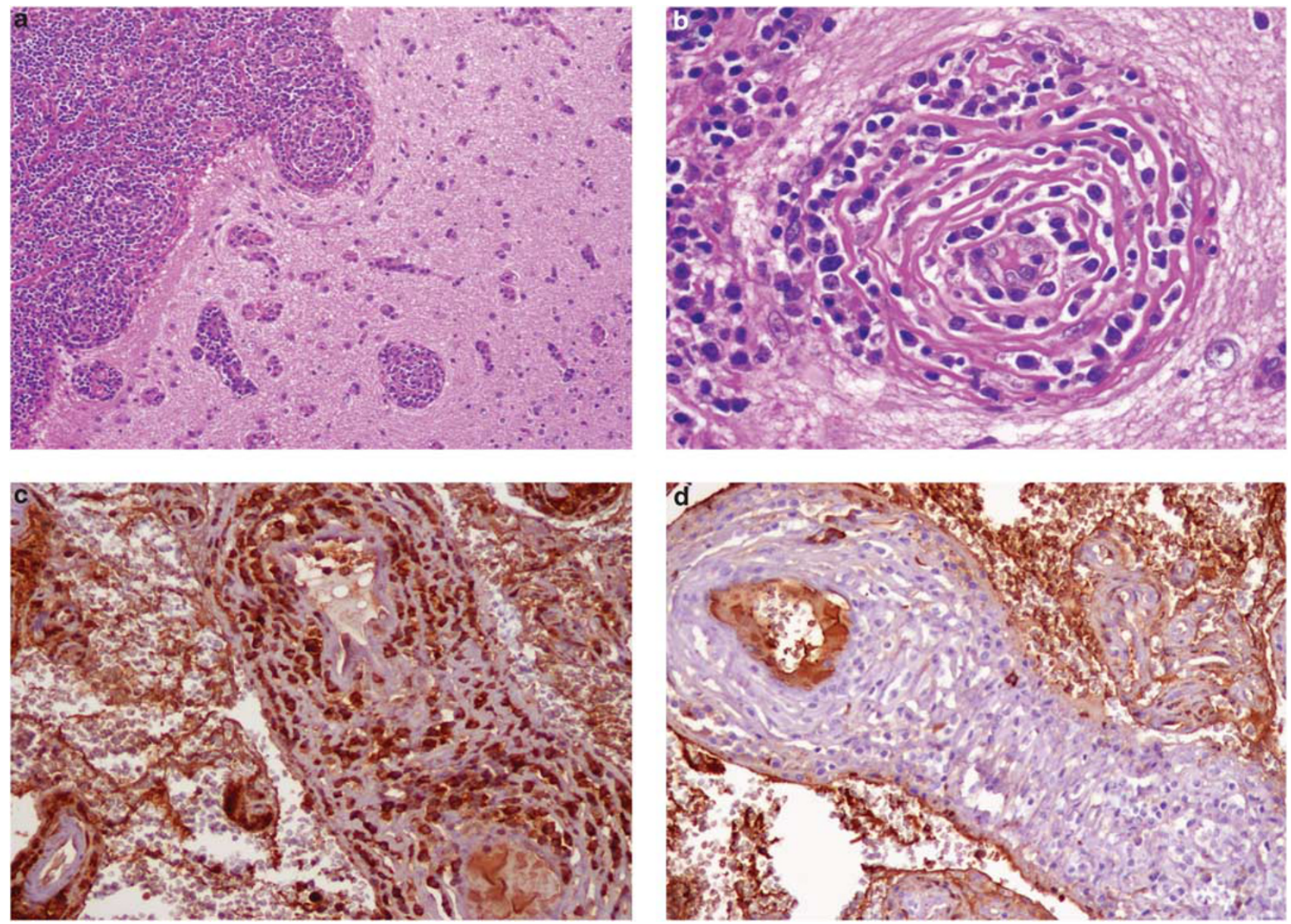

Figure 2 Involvement of the Virchow-Robin spaces and subjacent brain parenchyma. (a) Tumor abutting the surface of the brain parenchyma with subjacent focal involvement of Virchow-Robin space in case 31 (PAS stain). (b) Another case (case 25) with dense dural infiltrate of atypical lymphoplasmacytic cells. (c) $\lambda$-light chain restriction apparent in the perivascular plasmacytic cells. (d) $\kappa$-light chain stain is largely negative. This case additionally expressed monotypic IgG. 
Table 2 Histological differentiation and clonality analysis by light chain and PCR

\begin{tabular}{|c|c|c|c|c|c|}
\hline Case no. & Differentiation & Light chain & PCR & IgG4 status & Cytogenetic \\
\hline 1 & $\mathrm{P}$ & $\lambda$ & ND & ND & ND \\
\hline 2 & $\mathrm{P}$ & $\lambda$ & Clonal & ND & ND \\
\hline 3 & LP & $\kappa$ & Clonal & Negative & Normal \\
\hline 4 & LP & $\lambda$ & Clonal & Positive & Normal \\
\hline 5 & $\mathrm{P}$ & Equivocal & Clonal & ND & ND \\
\hline 6 & $\mathrm{~L}$ & $\kappa$ & Clonal & Negative & $+3,+18$ \\
\hline 7 & $\mathrm{~L}$ & Unsat & Clonal & ND & ND \\
\hline 8 & $\mathrm{P}$ & $\kappa$ & Clonal & Positive & Normal \\
\hline 9 & $\mathrm{P}$ & $\kappa$ & ND & ND & ND \\
\hline 10 & LP & $\kappa$ & No amplification & ND & $+1,+3$ \\
\hline 11 & $\mathrm{~L}$ & Polyclonal & Suspicious & Negative & ND \\
\hline 12 & $\mathrm{P}$ & Polyclonal & Clonal & ND & ND \\
\hline 13 & $\mathrm{P}$ & $\kappa$ & ND & ND & ND \\
\hline 14 & LP & $\kappa$ & Polyclonal & ND & ND \\
\hline 15 & $\mathrm{P}$ & $\lambda$ & Clonal & ND & ND \\
\hline 16 & LP & $\lambda$ & Clonal & Negative & ND \\
\hline 17 & LP & $\kappa$ & Polyclonal & Negative & ND \\
\hline 18 & LP & $\kappa$ & Clonal & Positive & ND \\
\hline 19 & $\mathrm{P}$ & $\kappa$ & ND & Negative & ND \\
\hline 20 & $\mathrm{P}$ & $\kappa$ & Polyclonal & Negative & ND \\
\hline 21 & LP & $\kappa$ & Clonal & Positive & ND \\
\hline 22 & $\mathrm{P}$ & $\kappa$ & Polyclonal & Negative & ND \\
\hline 23 & $\mathrm{~L}$ & Polyclonal & Clonal & Negative & Negative IGH/MALT \\
\hline 24 & LP & Polyclonal & Clonal & ND & ND \\
\hline 25 & $\mathrm{P}$ & $\lambda$ & ND & Negative & ND \\
\hline 26 & $\mathrm{P}$ & $\kappa$ & Clonal & Negative & ND \\
\hline 27 & $\mathrm{P}$ & $\lambda$ & Suspicious & Positive & Normal \\
\hline 28 & LP & $\lambda$ & Clonal & Positive & ND \\
\hline \multicolumn{6}{|c|}{ Cases with associated extradural disease } \\
\hline 29 & LP & Unsat & Clonal & Negative & Normal \\
\hline 30 & LP & Polyclonal & No amplification & Negative & Normal \\
\hline 31 & $\mathrm{P}$ & $\kappa$ & ND & ND & ND \\
\hline 32 & $\mathrm{~L}$ & $\kappa$ & Clonal & ND & 18 \\
\hline
\end{tabular}

Abbreviations: L, predominantly lymphocytic; LP, mixed lymphoid and plasmacytic; ND, not done; P, predominantly plasmacytoid.

In case 31, although the IGH was not performed on the dural lesion, the salivary gland lesion was clonal; in case, 32 the dural lesion showed $\kappa$-light chain restriction, and whereas PCR was performed only on the scalp biopsy which showed an IGH rearrangement.

Both cases with extradural disease (cases 30 and 32) were negative for IgG4 in the dural lymphoma and the skin lesion, respectively.

restricted plasmacytic population in 28 of 32 cases (as detailed in Table 2) with a preponderance of $\kappa$-light chain restriction. Colonization of reactive follicles by light-chain-restricted plasma cells was also apparent in 5 of 13 cases.

\section{IgG4 Immunohistochemistry}

We studied IgG4 expression in 20 of 32 cases, including 18 cases with primary dural lesions and 2 cases with extra-dural disease. In case 30, both lung and dural lesions were examined. Analysis for case 32 included the cutaneous lesion with no dural tissue available, yielding a total of 19 dural lymphomas tested for IgG4. The control tonsils showed many scattered strongly staining IgG4+ plasma cells in a sub-epithelial and parafollicular distribution that were much fewer in numbers than the corresponding IgG stain. The control case of autoimmune pancreatitis showed numerous strongly staining IgG4 + plasma cells throughout the lesion and around the ducts, as described (not shown). ${ }^{26}$
In the dural marginal zone lymphoma, 6 of 19 cases had markedly increased numbers of IgG4positive plasma cells, all of which demonstrated restricted light chain expression (Table 3). In case 6, colonized lymphoid follicles showed a similar spatial distribution pattern for IgG4 $+/ \lambda+$ plasma cells (Figure 3e). Also, the numbers of light-chainrestricted cells were commensurate to the numbers of IgG4-positive cells. In all, 12 of the 13 negative cases showed rare IgG4-positive plasma cells.

All IgG4 + cases were morphologically compared with the IgG4-negative marginal zone lymphoma in group A, specifically looking for presence of lymphoid follicles (see Table 3b), obstructive phlebitis, and sclerosis. One of the IgG4 + cases showed obstructive phlebitis (case 28, Figure 4), whereas another (case 27) was noted to have cuffing of venous channels by the atypical infiltrate (Figure 3f) and focal destructive infiltration of the arterial wall by atypical lymphoplasmacytic cells (see Figure 3g). Sclerosis was difficult to assess owing to the inherent dense, fibrous nature of dural tissue, which dissected through the atypical lymphoid infiltrate. 
Table 3 Marginal zone lymphomas with IgG4 expression

(a) Summary of IgG4-positive cases

\begin{tabular}{llcllll}
\hline Case No. & IgG4/IGG & Percent IgG4 & Light chain & PCR clonality & $\begin{array}{c}\text { Cytogenetic } \\
\text { abnormality }\end{array}$ & $\begin{array}{c}\text { Lymphoid } \\
\text { follicles }\end{array}$ \\
\hline 4 & $210 / 267$ & 79 & $\lambda$ & Clonal & None & - \\
phlebitis
\end{tabular}

(b) Frequencies of various morphologic features examined in all cases and the subset tested for IgG4

All cases $(\mathrm{n}=32)$

IgG4 tested subset

Significance $^{\mathrm{b}}$

IgG4 positive $(\mathrm{n}=6) \quad$ IgG4 negative $(\mathrm{n}=13)$

\begin{tabular}{|c|c|c|c|c|}
\hline Plasmacytosis & $28 / 32$ & $6 / 6$ & $12 / 13$ & 0.91 \\
\hline Lymphoid follicles & $13 / 32$ & $3 / 6$ & $6 / 13$ & 0.23 \\
\hline Follicular colonization & $5 / 13$ & $2 / 3$ & $2 / 5$ & 0.2 \\
\hline
\end{tabular}

Abbreviation: ND, not done.

${ }^{a}$ Case 27 yielded a distinct peak in one of the IG $\kappa$ reactions, albeit of a lower intensity than the threshold used by our laboratory for calling a positive result.

${ }^{\mathrm{b}} P$-values from either $\chi^{2}$ or Fisher's exact test analyzing the significance of differences in proportions of cases stratified by IgG4 expression status.

Nevertheless, we were able to ascertain presence of sclerosis in areas away from the dura in case 18.

The three cases of dural inflammatory pseudotumors were characterized by a prominent myofibroblastic and/or inflammatory component rich in a polymorphous population of inflammatory cells including plasma cells. None of these cases demonstrated monotypic light chain restriction (three out of three) or clonality by PCR in two of three cases; furthermore, only occasional scattered IgG4-positive plasma cells (ranging from 8-10 IgG4/HPF) were present in all cases (data not shown; see Supplementary Figure illustrating a representative inflammatory pseudotumor).

\section{PCR studies for B-cell clonality}

Among 23 of 32 informative cases, 18 were clonal, whereas 2 were suspicious for a significant clonal rearrangement (Table 2). Although the remaining three were polyclonal by PCR, all were light chain restricted. Most of the IgG4-positive cases were clonal by PCR (five of six) with all six being light chain restricted.

\section{FISH and RT-PCR}

FISH for common MALT lymphoma associated translocations and trisomies were performed on nine cases (see Table 2) with genetic aberrations seen in three cases (including two primary dural and one with extra-dural disease, see Figure 1e). Trisomy 1 was verified with a specific centromere 1 probe. Trisomy 12 was not present in any of the cases examined.

RT-PCR was used for the detection of the API2$M A L T 1$ fusion transcript and FISH was used for the detection of $\mathrm{t}(14 ; 18)(\mathrm{q} 32 ; \mathrm{q} 21), B C L 10$ and FOXP1. In addition, dual color break-apart probes were used for $I G H$ and $B C L 6$ genetic alterations. None of these known MALT lymphoma-associated translocations were detected in any of the cases (data not shown; see Supplementary Information depicting table of results using various probes in each case). Notably, three IgG4-positive cases tested among these nine cases did not show any aberrations. In addition, FISH performed at the referring institution on case 24 reportedly indicated no evidence of IGH or MALT1 translocations.

\section{Discussion}

Although lymphoplasmacytic proliferations had been described in the dura, in 1997 our group first recognized them as part of the spectrum of marginal zone lymphoma of MALT type. ${ }^{5}$ Since our original report, several other publications have confirmed a small risk for MALT lymphoma in this site. ${ }^{7,32-38}$ Among lymphomas primary to the dura, marginal zone lymphoma is reportedly the most common type. However, these cases are still relatively rare and with limited data regarding their clinical behavior. Therefore, we investigated the histological, immunohistochemical and molecular characteristics 

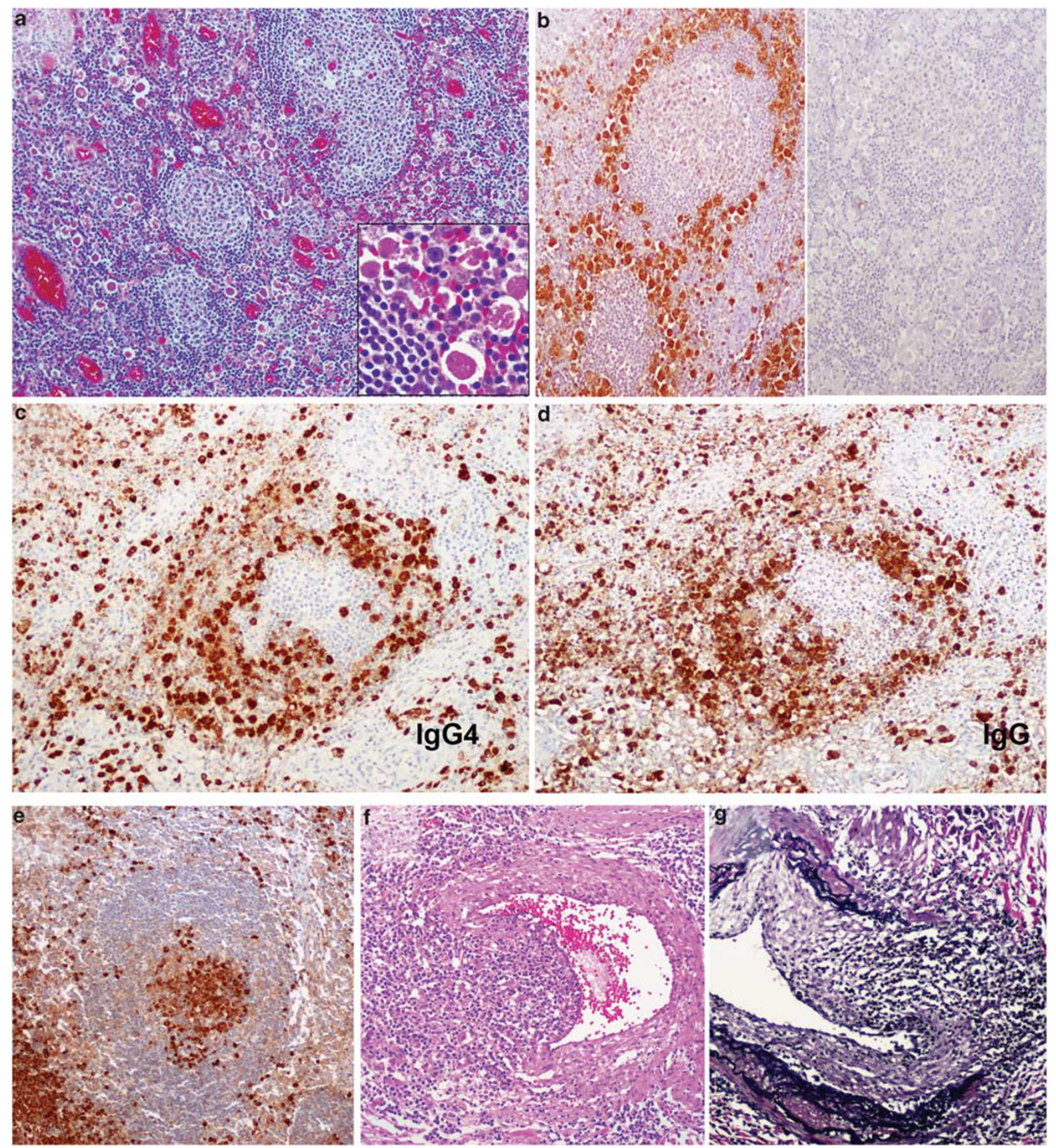

Figure 3 Histological findings in IgG4-positive cases. (a) Case 8 with many scattered reactive lymphoid follicles rimmed by Mott cells (inset). (b) $\kappa$-restriction is apparent in the parafollicular population of plasmacytic cells (case 8). (c, d) IgG4 marks a commensurate number of cells with plasmacytic differentiation in a similar spatial distribution as the corresponding IgG stain (case 8). (e) Case 27 shows numerous IgG4-positive cells colonizing the follicles. (f). This case additionally showed medium sized muscular vascular channels showing tufting encroachment of the wall by cells with plasmacytic differentiation. (g) Focal transmural arterial wall invasion by the lymphoid infiltrate with disruption of the internal elastic lamina (case 27). These areas showed numerous IgG4-positive plasma cells (elastic Van Gieson).

of 32 dural marginal zone lymphomas. Our series confirms the clinical spectrum of dural MALT lymphomas. In this series, there was a marked female predominance. The clinical presentation was typified by seizures, dizziness or localized
CNS specific symptoms due to mass effect (focal neurological defects). Radiologically, the majority of the lesions presented as a dural-based mass mimicking meningioma, with a minority presenting as dural thickening (en plaque type). The referring clinical 

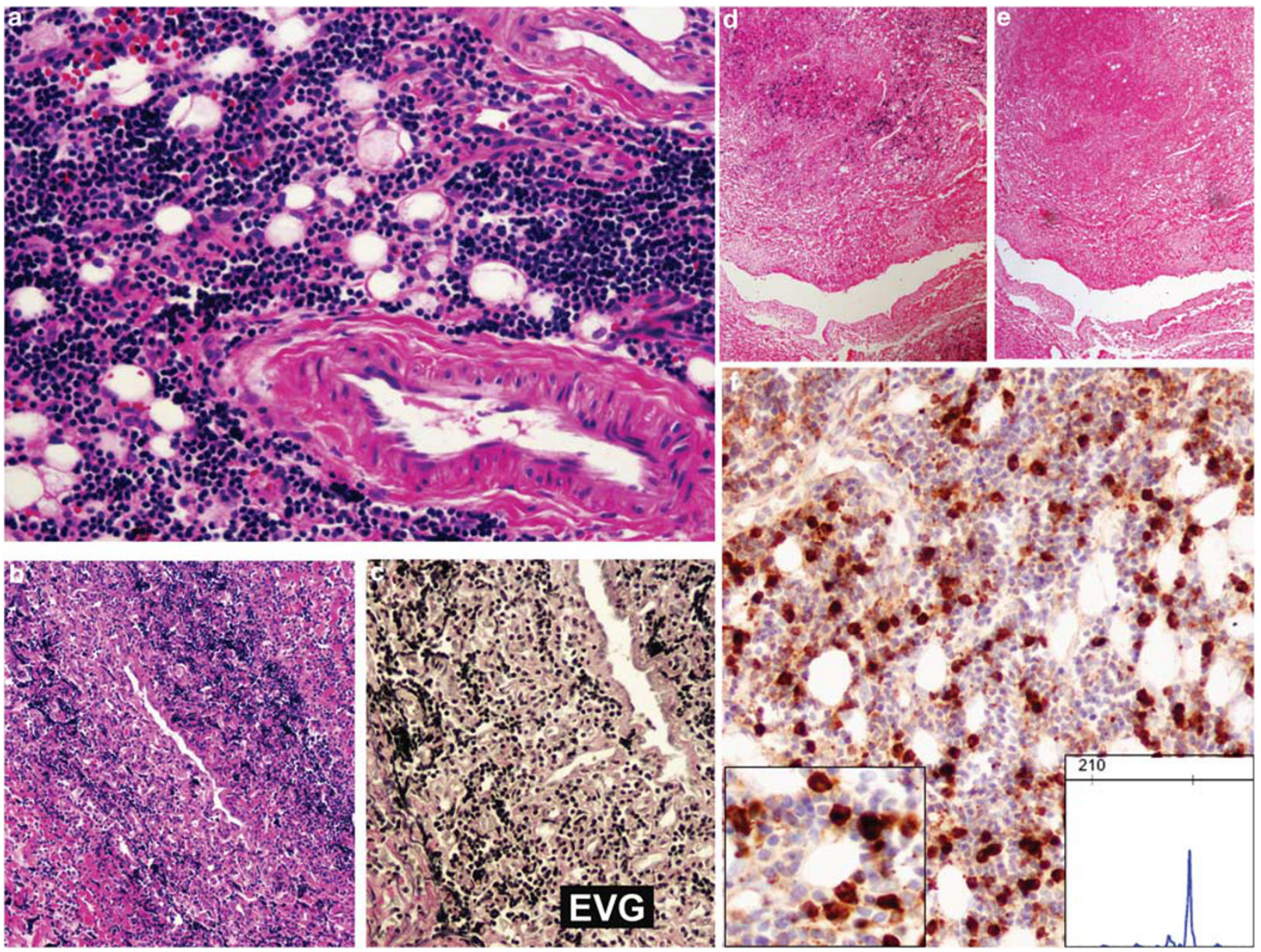

Figure 4 IgG4-positive thoracic epidural dural tumor (case 28). (a) Atypical lymphoid infiltrate permeating fibrous and adipose tissue. $(\mathbf{b}, \mathbf{c})$ Obstructive phlebitis with dense transmural lymphoid infiltrate. (d, e) $\lambda$-light-chain-restricted plasmacytic population readily unmasked by in situ hybridization. (f) Numerous IgG4-positive cells with plasmacytic differentiation (left inset); PCR testing at the IGk locus yielded a distinct $238 \mathrm{bp}$ size clonal population (right inset).

diagnosis in a majority of the cases was meningioma or, in four cases, subdural hematoma. The latter presentation has been reported previously in dural marginal zone lymphoma. ${ }^{33,39}$ Irrespective of the treatment modalities (radiation, chemotherapy or combined modality) used in our study, complete remission was achieved in most patients with no evidence of recurrence.

Histologically, all tumors in our study showed a predominant atypical B-cell component with variable numbers of admixed reactive T cells. Scattered reactive follicles were present in approximately a third of the cases. Plasmacytic differentiation was present in most cases with clonality by light chain restriction and/or IGH rearrangement in all but one case. The fact that two cases showed variable infiltration into of the adjacent brain or cranial nerves might suggest a locally aggressive feature, at least in a subset of cases. However, in the series of Iwamoto et $a l,{ }^{6}$ no CNS relapse was noted, despite positive involvement of the Virchow-Robin spaces by tumor in five out of eight cases.
A recent study from Mayo clinic indicated that patients with IgG4-related sclerosing disease may have an increased risk of developing nonHodgkin's lymphoma, ${ }^{40}$ a finding echoed in earlier reports of marginal zone lymphomas expressing monotypic light chain and IgG4. ${ }^{24,25,41}$ Although marginal zone lymphomas-expressing IgG4 have not been described in the dural location to date, the recent description of the occurrence of an IgG4-related sclerosing pachymeningitis ${ }^{19}$ in the thoracic dura indicates that IgG4 may also have a role in dural marginal zone lymphoma. Hence, we sought to investigate whether IgG4 expression was present in intracranial dural and thoracic epidural lesions.

In all, 6 of 19 primary cases expressed monotypic IgG4 with light-chain-restricted plasma cells spatially corresponding to the IgG4 + cells supporting their designation as IgG4-positive marginal zone lymphomas, including the one involving the thoracic spine, in contrast to the case described by Chan et $a l,{ }^{19}$ where clonality was not found. 
The IgG4 + dural marginal zone lymphomas in our series resemble other extranodal marginal zone lymphomas, such as the ones recently described in the ocular adnexae. ${ }^{24,25}$ Sato et $a l^{25}$ initially identified two cases of clonal B-cell proliferations among 17 cases of ocular adnexal IgG4-related disease. Although light chain restriction was not evaluated, the two cases were reclassified as marginal zone lymphoma based on the molecular results. Subsequently, this group reported a case of an IgG4positive marginal zone lymphoma with monotypic light chain expression and clonal PCR studies. ${ }^{41}$ In another study, specifically addressing the issue of de novo vs progression in IgG4 + marginal zone lymphoma, Cheuk et $a l^{42}$ reported a series comprising five orbital marginal zone lymphoma harboring high proportions of IgG4 + plasma cells. Two of their cases had evidence of antecedent IgG4-related sclerosing disease, whereas three cases expressed monotypic IgG4 with no preexisting IgG4-related sclerosing disease components, purportedly representing de novo IgG4 + marginal zone lymphomas. Although we cannot categorically exclude a preexisting IgG4-related sclerosing disease state, none of our IgG4 + cases showed an apparent second polyclonal plasma cell population in addition to the light-chain-restricted component to suggest a preexistent polyclonal IgG4-related state. Second, all IgG4-negative cases revealed only rare IgG4 + cells amidst a much larger light-chain-restricted population. These features may indicate that our cases may presumably represent de novo IgG4 + dural marginal zone lymphomas.

A subset of hepatic, ${ }^{17}$ lung $^{16}$ and more recently intracranial inflammatory pseudotumors have been shown to have variable numbers of IgG4-positive plasma cells, although the temporal relationship and biologic relevance of inflammatory pseudotumors to IgG4-related sclerosing disease or subsequent lymphoma is still unclear. In light of these studies, we evaluated three inflammatory pseudotumors from our archives for IgG4 expression, and we did not find significant numbers of IgG4-positive cells in any of these three cases (ranging from 8-10 IgG4/HPF; mild per criteria of Kamisawa et $a l^{12}$ ), in contrast to the intracranial cases reported by Lui et $a l,{ }^{43}$ wherein three out of four cases showed a relative increase of IgG4-positive plasma cell in a rich inflammatory background.

Although the number of cases studied for genetic alterations is small and precludes generalization, trisomy 3 remains the most frequent aberration as also reported by Tu et al. ${ }^{7}$ Although there is a single report documenting a dural marginal zone lymphoma with IGH/MALT-1 translocation, ${ }^{8}$ our study failed to detect MALT- or IGH-related translocations, in concurrence with the findings of $\mathrm{Tu}$ et al. ${ }^{7} \mathrm{In}$ addition, none of these genetic alterations were detected in the IgG4-positive dural marginal zone lymphomas tested, (Table 3) suggesting that dural marginal zone lymphomas may be distinct from orbital MALT lymphomas, which harbor IGH translocations in a significant proportion of cases. ${ }^{11}$

In summary, we reviewed a large series of primary dural marginal zone lymphoma and identified a significant association with IgG4 expression. In addition, we demonstrated clonality in all of the IgG4-positive cases, indicating that IgG4-producing cells can be neoplastic. It remains unclear whether these cases represent lymphoma arising in a background of IgG4-sclerosing disease or de novo IgG4positive marginal zone lymphoma.

\section{Acknowledgements}

We thank Liqiang Xi, MD of our molecular laboratory for his assistance with interpretation of the molecular studies and also acknowledge the help of our immunohistochemistry laboratory for their help with the immunostains. Lastly, we also acknowledge the contribution of Steven J Kussick MD, PhD of Phenopath labs (Seattle, WA) for his technical input with optimization of the IgG4 staining protocol.

\section{Disclosure/conflict of interest}

The authors declare no conflict of interest.

\section{References}

1 Altundag MK, Ozisik Y, Yalcin S, et al. Primary low grade B-cell lymphoma of the dura in an immunocompetent patient. J Exp Clin Cancer Res 2000;19:249-251.

2 Itoh T, Shimizu M, Kitami K, et al. Primary extranodal marginal zone B-cell lymphoma of the mucosa-associated lymphoid tissue type in the CNS. Neuropathology 2001;21:174-180.

3 Kambham N, Chang Y, Matsushima AY. Primary lowgrade B-cell lymphoma of mucosa-associated lymphoid tissue (MALT) arising in dura. Clin Neuropathol 1998;17:311-317.

4 Sanjeevi A, Krishnan J, Bailey PR, et al. Extranodal marginal zone B-cell lymphoma of malt type involving the cavernous sinus. Leuk Lymphoma 2001;42:1133-1137.

5 Kumar S, Kumar D, Kaldjian EP, et al. Primary lowgrade B-cell lymphoma of the dura: a mucosa associated lymphoid tissue-type lymphoma. Am J Surg Pathol 1997;21:81-87.

6 Iwamoto FM, DeAngelis LM, Abrey LE. Primary dural lymphomas: a clinicopathologic study of treatment and outcome in eight patients. Neurology 2006;66:1763-1765.

7 Tu PH, Giannini C, Judkins AR, et al. Clinicopathologic and genetic profile of intracranial marginal zone lymphoma: a primary low-grade CNS lymphoma that mimics meningioma. J Clin Oncol 2005;23:5718-5727.

8 Bhagavathi S, Greiner TC, Kazmi SA, et al. Extranodal marginal zone lymphoma of the dura mater with $\mathrm{IgH} /$ MALT1 translocation and review of literature. J Hematop 2008;1:131-137.

9 Streubel B, Simonitsch-Klupp I, Mullauer L, et al. Variable frequencies of MALT lymphoma-associated genetic aberrations in MALT lymphomas of different sites. Leukemia 2004;18:1722-1726. 
10 Inagaki H. Mucosa-associated lymphoid tissue lymphoma: molecular pathogenesis and clinicopathological significance. Pathol Int 2007;57:474-484.

11 Streubel B, Vinatzer U, Lamprecht A, et al. T(3;14) (p14.1;q32) involving IGH and FOXP1 is a novel recurrent chromosomal aberration in MALT lymphoma. Leukemia 2005;19:652-658.

12 Kamisawa T, Nakajima H, Hishima T. Close correlation between chronic sclerosing sialadenitis and immunoglobulin G4. Intern Med J 2006;36:527-529.

13 Deheragoda MG, Church NI, Rodriguez-Justo M, et al. The use of immunoglobulin g4 immunostaining in diagnosing pancreatic and extrapancreatic involvement in autoimmune pancreatitis. Clin Gastroenterol Hepatol 2007;5:1229-1234.

14 Yamamoto M, Ohara M, Suzuki C, et al. Elevated IgG4 concentrations in serum of patients with Mikulicz's disease. Scand J Rheumatol 2004;33:432-433.

15 Geyer JT, Ferry JA, Harris NL, et al. Chronic sclerosing sialadenitis (Kuttner tumor) is an IgG4-associated disease. Am J Surg Pathol 2010;34:202-210.

16 Zen Y, Kitagawa S, Minato H, et al. IgG4-positive plasma cells in inflammatory pseudotumor (plasma cell granuloma) of the lung. Hum Pathol 2005;36:710-717.

17 Zen Y, Fujii T, Sato Y, et al. Pathological classification of hepatic inflammatory pseudotumor with respect to IgG4-related disease. Mod Pathol 2007;20:884-894.

18 Cheuk W, Yuen HK, Chu SY, et al. Lymphadenopathy of IgG4-related sclerosing disease. Am J Surg Pathol 2008;32:671-681.

19 Chan SK, Cheuk W, Chan KT, et al. IgG4-related sclerosing pachymeningitis: a previously unrecognized form of central nervous system involvement in IgG4-related sclerosing disease. Am J Surg Pathol 2009;33:1249-1252.

20 Tanabe T, Tsushima K, Yasuo M, et al. IgG4-associated multifocal systemic fibrosis complicating sclerosing sialadenitis, hypophysitis, and retroperitoneal fibrosis, but lacking pancreatic involvement. Intern Med 2006;45:1243-1247.

21 Yamamoto M, Naishiro Y, Suzuki C, et al. Proteomics analysis in 28 patients with systemic IgG4-related plasmacytic syndrome. Rheumatol Int 2010;30:565-568.

22 Yamamoto $M$, Takahashi $\mathrm{H}$, Ohara $\mathrm{M}$, et al. A new conceptualization for Mikulicz's disease as an IgG4-related plasmacytic disease. Mod Rheumatol 2006;16:335-340.

23 Bateman AC, Deheragoda MG. IgG4-related systemic sclerosing disease - an emerging and under-diagnosed condition. Histopathology 2009;55:373-383.

24 Cheuk W, Yuen HK, Chan JK. Complication of IgG4related chronic sclerosing dacryoadenitis by lymphoma. Arch Ophthalmol 2008;126:1170; author reply.

25 Sato Y, Ohshima K, Ichimura K, et al. Ocular adnexal IgG4-related disease has uniform clinicopathology. Pathol Int 2008;58:465-470.

26 Yamamoto H, Yamaguchi H, Aishima S, et al. Inflammatory myofibroblastic tumor versus IgG4-related sclerosing disease and inflammatory pseudotumor: a comparative clinicopathologic study. Am J Surg Pathol 2009;33:1330-1340.

27 Ramasamy I, Brisco M, Morley A. Improved PCR method for detecting monoclonal immunoglobulin heavy chain rearrangement in B cell neoplasms. J Clin Pathol 1992;45:770-775.
28 van Dongen JJ, Langerak AW, Bruggemann $\mathrm{M}$, et al. Design and standardization of PCR primers and protocols for detection of clonal immunoglobulin and T-cell receptor gene recombinations in suspect lymphoproliferations: report of the BIOMED-2 concerted action BMH4-CT98-3936. Leukemia 2003;17:2257-2317.

29 Inagaki H, Okabe M, Seto M, et al. API2-MALT1 fusion transcripts involved in mucosa-associated lymphoid tissue lymphoma: multiplex RT-PCR detection using formalin-fixed paraffin-embedded specimens. Am J Pathol 2001;158:699-706.

30 Streubel B, Lamprecht A, Dierlamm J, et al. T(14;18) (q32;q21) involving IGH and MALT1 is a frequent chromosomal aberration in MALT lymphoma. Blood 2003;101:2335-2339.

31 Ye $\mathrm{H}$, Liu H, Attygalle A, et al. Variable frequencies of $\mathrm{t}(11 ; 18)(\mathrm{q} 21 ; \mathrm{q} 21)$ in MALT lymphomas of different sites: significant association with CagA strains of $\mathrm{H}$ pylori in gastric MALT lymphoma. Blood 2003;102:1012-1018.

32 George AC, Ozsahin M, Janzer R, et al. Primary intracranial dural lymphoma of mucosa-associated lymphoid tissue (MALT) type: report of one case and review of the literature. Bull Cancer 2005;92:E51-E56.

33 Goetz P, Lafuente J, Revesz T, et al. Primary low-grade B-cell lymphoma of mucosa-associated lymphoid tissue of the dura mimicking the presentation of an acute subdural hematoma. Case report and review of the literature. J Neurosurg 2002;96:611-614.

34 Iwamoto FM, Abrey LE. Primary dural lymphomas: a review. Neurosurg Focus 2006;21:E5.

35 Miller M, Loffe V, Ruffin WK, et al. Primary MALT lymphoma of the dura in a patient with active scleroderma. Clin Adv Hematol Oncol 2004;2:815-819.

36 Razaq W, Goel A, Amin A, et al. Primary central nervous system mucosa-associated lymphoid tissue lymphoma: case report and literature review. Clin Lymphoma Myeloma 2009;9:E5-E9.

37 Saggioro FP, Colli BO, Paixao-Becker AN, et al. Primary low-grade MALT lymphoma of the dura. Histopathology 2006;49:323-326.

38 Bayraktar S, Stefanovic A, Montague N, et al. Central nervous system manifestations of marginal zone B-cell lymphoma. Ann Hematol 2010;89:1003-1009.

39 Gocmen S, Gamsizkan M, Onguru O, et al. Primary dural lymphoma mimicking a subdural hematoma. J Clin Neurosci 2010;17:380-382.

40 Takahashi N, Ghazale AH, Smyrk TC, et al. Possible association between IgG4-associated systemic disease with or without autoimmune pancreatitis and nonHodgkin lymphoma. Pancreas 2009;38:523-526.

41 Sato Y, Takata K, Ichimura K, et al. IgG4-producing marginal zone B-cell lymphoma. Int J Hematol 2008;88:428-433.

42 Cheuk W, Yuen HK, Chan AC, et al. Ocular adnexal lymphoma associated with IgG4+ chronic sclerosing dacryoadenitis: a previously undescribed complication of IgG4-related sclerosing disease. Am J Surg Pathol 2008;32:1159-1167.

43 Lui PC, Fan YS, Wong SS, et al. Inflammatory pseudotumors of the central nervous system. Hum Pathol 2009;40:1611-1617.

44 Shaia J, Kerr PB, Saini A, et al. Mucosa-associated lymphoma tissue of the dura presenting as meningioma. South Med J 2010;103:950-952. modpathol) 